\title{
Increasing Destructive Potential of Landfalling Tropical Cyclones over China
}

\author{
LU LIU \\ State Key Laboratory of Severe Weather, Chinese Academy of Meteorological Sciences, Beijing, China \\ YUQING WANG \\ International Pacific Research Center, and Department of Atmospheric Sciences, School of Ocean and Earth Science and \\ Technology, University of Hawai'i at Mānoa, Honolulu, Hawaii, and State Key Laboratory of Severe Weather, Chinese \\ Academy of Meteorological Sciences, Beijing, China \\ RUIFEN ZHAN \\ Department of Atmospheric and Oceanic Sciences, Fudan University, Shanghai, China \\ JING XU AND YIHONG DUAN \\ State Key Laboratory of Severe Weather, Chinese Academy of Meteorological Sciences, Beijing, China
}

(Manuscript received 19 June 2019, in final form 17 December 2019)

\begin{abstract}
This study investigates the trend in destructive potential of landfalling tropical cyclones (TCs) in terms of power dissipation index (PDI) over mainland China in the period of 1980-2018. Results show that both the accumulated PDI and averaged PDI after landfall show significant increasing trends. The increasing trends are found to be contributed primarily by the increasing mean duration of TCs over land and the increasing TC intensity at landfall. Further analyses indicate that the increase in landfalling TC intensity prior to and at landfall, the decrease in intensity weakening rate after landfall, and the northward shift of landfalling TC track density all contribute to the longer duration of TCs after landfall. Moreover, the conducive large-scale conditions, such as the increases in coastal sea surface temperature and land surface temperature and soil moisture, the decrease in low-level vertical wind shear, and the increase in upper-level divergence, are all favorable for intense landfalling TCs and their survival after landfall, thus contributing to the increasing destructive potential of landfalling TCs over China.
\end{abstract}

\section{Introduction}

Landfalling tropical cyclones (TCs), in particular intense TCs, can cause casualties and severe property losses (Zhang et al. 2009). Previous studies have demonstrated that the socioeconomic losses caused by TCs increased dramatically in recent decades (Pielke et al. 2008; Zhang et al. 2009). For example, the averaged economic losses resulting from one landfalling $\mathrm{TC}$ in the Korean Peninsula and Japan amounted to almost 1 billion U.S. dollars, which was 3 times as high as those in the 1980s (Park et al. 2011). Therefore, understanding the characteristics of landfalling TCs and their long-term trend is essential for both public and research society.

Previous studies have shown that there has been a significant increase in destructive power and intensity

Corresponding author: Prof. Yuqing Wang, yuqing@hawaii.edu of TCs over the western North Pacific Ocean (WNP) in response to global warming (Knutson and Tuleya 2004; Emanuel 2005; Webster et al. 2005; Klotzbach 2006; Knutson et al. 2007; Elsner et al. 2008; Knutson et al. 2010; Park et al. 2013). Emanuel (2005) revealed that the power dissipation index (PDI) of TCs over the WNP had increased significantly in the past three decades. Webster et al. (2005) revealed a trend toward more frequent intense TCs over the past 35 years. Wu et al. (2008) found that the moderate increase in the accumulated PDI over the WNP was primarily due to the significant increase in the averaged TC intensity.

Most of previous studies have investigated the longterm changes of TCs over the WNP, but some recent studies have paid more attention to the characteristics of TCs after landfall because most of the damages caused by TCs are related to landfalling TCs (Chen et al. 2011; Park et al. 2011, 2014; Li et al. 2017). Chen et al. (2011) 
examined 233 TCs that made landfall over mainland China and found a marked increase in the annual average overland duration of TCs from 1975 to 2009. Park et al. (2011) analyzed the long-term changes in TCs after landfall over the Korean peninsula and Japan and revealed that the PDI and TC duration after landfall had increased significantly in recent decades. Park et al. (2014) found a shift of location of intense TCs along the East Asian coastline during 1977-2010 and a robust increase in landfalling TC intensity over East Asia. Recently, Li et al. (2017) investigated the changes in the destructive potential of TCs over China during 1975-2014 and confirmed that TCs making landfall over East China tended to be more destructive in recent decades. They showed that such an increase is associated with the increase in frequency and intensity of landfalling TCs.

Although these studies have focused on changes in landfalling TCs over East Asia, understanding changes in the characteristics of landfalling TCs and TCs after landfall over mainland China and the mechanisms responsible for their changes still needs to be improved and deepened. Some issues are yet to be addressed, including whether any long-term changes in the characteristics of landfalling TCs and TCs after landfall over mainland China occur and what control the long-term changes in TC destructive potential after landfall over mainland China. The objective of this study is to analyze the trends in destructive potential of landfalling TCs in terms of PDI over mainland China during 1980-2018 and to identify factors and mechanisms that are responsible for the observed long-term trends. We will show that both the accumulated PDI and averaged PDI increased significantly in the studied period and such an increase is primarily due to the increase in both landfalling TC intensity and the mean duration of TCs over land. The latter increase is mainly associated with the increase in coastal sea surface temperature, and land surface temperature and soil moisture, the decrease in vertical wind shear, and the increase in upper-level divergence.

The rest of the paper is organized as follows. Section 2 describes the data and analysis methods used in this study. The temporal changes in the observed landfalling TC characteristics are presented in section 3. Section 4 examines the possible factors contributing to the observed changes and the involved mechanisms. The main findings are summarized and briefly discussed in section 5 .

\section{Data and analysis methods}

The best-track TC data used in this study are acquired from the China Meteorological Administration-Shanghai Typhoon Institute (CMA/STI), which include latitude and longitude of the TC center, TC intensity in terms of the maximum sustained (2-min mean), 10-m wind speed, and minimum sea level pressure at 6 -h intervals. The best-track TC datasets from the Joint Typhoon Warning Center (JTWC), the Hong Kong Observatory (HKO), and the Regional Specialized Meteorological Center of the Japan Meteorological Agency (JMA) are also used to check the robustness of our results based on the CMA/STI best-track dataset. Note that different time averages are used to define the sustained maximum 10-m wind speed for TC intensity among these best-track datasets. We did not convert TC intensity from different agencies into the same time averaging because we focus on the linear trend analysis and the conversion should not affect the trends qualitatively. In this study, the CMA/STI best-track dataset is used as the primary TC data because relatively more observational data were available over mainland China when the postseason TC analysis was conducted to generate the best-track TC data. Actually, the annual postseason analysis of TC data is performed by STI/CMA to reduce uncertainties and improve the accuracy using all available data, including station observations, ship weather reports, automated surface observations, synoptic charts, radiosonde data, aircraft reconnaissance, satellite, coastal radar observations, and the real-time TC warming advice from various agencies (Ying et al. 2014).

We only consider TCs making landfall over mainland China (excluding those making landfall over Taiwan or Hainan Island) during 1980-2018. A landfalling TC refers to a TC whose center crossed the coastline of mainland China at least once during its lifetime in this study. Only TCs with maximum sustained wind speed exceeding $17.2 \mathrm{~m} \mathrm{~s}^{-1}$ at and after landfall during the peak typhoon season between June-October are included in our analyses.

The European Centre for Medium-Range Weather Forecasts (ECMWF) interim reanalysis (ERA-Interim) data at the horizontal resolution of $0.75^{\circ} \times 0.75^{\circ}($ Dee et al. 2011) are used to examine the large-scale environmental conditions and their changes responsible for the observed changes in the characteristics of landfalling TCs over mainland China. The sea surface temperature (SST) is obtained from NOAA's Optimum Interpolation Sea Surface Temperature (OISST), which is a series of global analysis products including the daily SST at the resolution of $0.25^{\circ} \times 0.25^{\circ}$. The soil moisture is obtained from the NOAA Gridded Climate Dataset with the horizontal resolution of $0.5^{\circ} \times 0.5^{\circ}$.

Many metrics have been used to characterize TC activity, such as the accumulated cyclone energy (Camargo and Sobel 2005; Trenberth 2005), integrated kinetic energy (Powell and Reinhold 2007), and PDI (Emanuel 
2005, 2007; Kossin et al. 2007). One common measure of the TC destructive potential is the PDI, which is defined as the sum of the cubes of the maximum sustained wind speed $v$ over the entire lifetime of a TC (Emanuel 2005; Park et al. 2011; Li et al. 2017). The accumulated PDI is calculated by summing the PDI of individual TCs over a particular TC season. The accumulated TC PDI is defined as

$$
\mathrm{PDI}=\sum_{n=1}^{N} \sum_{t=1}^{T} v_{\max }^{3},
$$

where $N$ is the total number of landfalling TCs in a TC season in a certain year and $T$ is the duration of landfalling TCs with 6-h intervals (Emanuel 2005). The average PDI in the year is obtained by dividing the above PDI by the total number $N$ of landfalling TCs in the year. The landfalling time is defined as the time when the TC center reached the coastline of mainland China, and the TC intensity at landfall is linearly interpolated using the 6-hourly TC position in the best-track data ( $\mathrm{Hu}$ et al. 2017). Note that if the path of the TC reentered the sea we only consider the period of the TC when it was over land. The duration after landfall of a TC is defined as the period from the TC center crossing the coastline (at landfall) to the first record in the best-track data when the TC intensity became less than $17.2 \mathrm{~m} \mathrm{~s}^{-1}$ (i.e., became a tropical depression in the best-track data). The weakening rate of a landfalling TC is defined as the intensity (in terms of maximum 10-m sustained wind speed) difference between the time of landfall and the time when the TC became a tropical depression divided by the duration of the storm over land after landfall.

\section{Trend analysis for landfalling TCs over mainland China}

Figure 1 shows the time series of the accumulated PDI and average PDI of TCs after landfall during 1980-2018. The accumulated PDI exhibits a significant upward trend, which is statistically significant over $90 \%$ confidence level. It increases from about $1 \times 10^{6}$ to about $1.6 \times 10^{6} \mathrm{~m}^{3} \mathrm{~s}^{-3}$, namely an increase of $60 \%$ over the past 39 years (Fig. 1a). Similarly, the average PDI shows a robust increase over this period with the statistical significance being over the $98 \%$ confidence level (Fig. 1b), while the landfall TC frequency (Fig. 2a) shows no apparent increasing or decreasing trend over the studied period (on average about three to four TCs made landfall over mainland China per year). This strongly suggests that the increasing trend in the accumulated PDI is mainly contributed by the increasing trend in the average PDI. This also implies that the destructive potential of an individual TC has increased over the past $30-40$ years. To confirm the above results, similar analyses are also conducted using the JTWC, JMA, and HKO best-track datasets with the results shown in Figs. 1c and 1d. All three datasets display a significant increasing trend in both the accumulated PDI and averaged PDI. The trend in the HKO dataset is a little lower but closest to that in the CMA dataset. The trend from the JTWC dataset is much higher than that from CMA dataset partly due to the 1-min averaging of sustained 10-m wind speed used by JTWC and 2-min averaging used by CMA. However, the trend from the JMA dataset is much lower than the trends in other datasets partly because the JMA dataset stopped TC records inland too early and partly because the JMA uses 10-min averaging for maximum sustained 10-m wind speed.

Different from the results of Li et al. (2017), who found that the increasing PDI over East China was mainly due to the landfall frequency and landfall intensity, our analyses show that the increase in average PDI is primarily contributed by the increase in the mean duration over land after landfall (Fig. 2b). Indeed, the increase in the mean duration is statistically significant over $98 \%$ confidence level. In addition to the mean duration, the mean TC intensity also contributes to the increasing average PDI, but is less significant (Fig. 2c). The increasing trend of the mean duration over land is consistent with the finding of Chen et al. (2011), who first noticed the increasing mean overland duration of TCs after landfall over mainland China. They found that the increasing mean overland duration was mainly contributed by both the decreasing translation speed and the increasing inland traveling distance. Compared with the results of Chen et al. (2011), our results show some different contributions to the increasing duration over land. Although the mean traveling distance after landfall also shows significant increasing trend (Fig. 3a), a weak increasing trend appears to the mean translation speed over land (Fig. 2d), which is in contrast with the results of Chen et al. (2011). We can see from Fig. 1c of Chen et al. (2011) that it was a peak speed during 1975-80 that caused a significant decreasing trend for the following years. Our results thus strongly suggest that the variation of the mean translation speed over land contributed little to the increasing mean duration after landfall over the past $30-40$ years. In addition to the translation speed and the traveling distance over land, several other factors, such as landfall intensity, weakening rate over land, and landfall location and predominant TC track, may also contribute to overland duration. Note that in addition to the linear increasing trend, the overland duration also experienced a sharp 

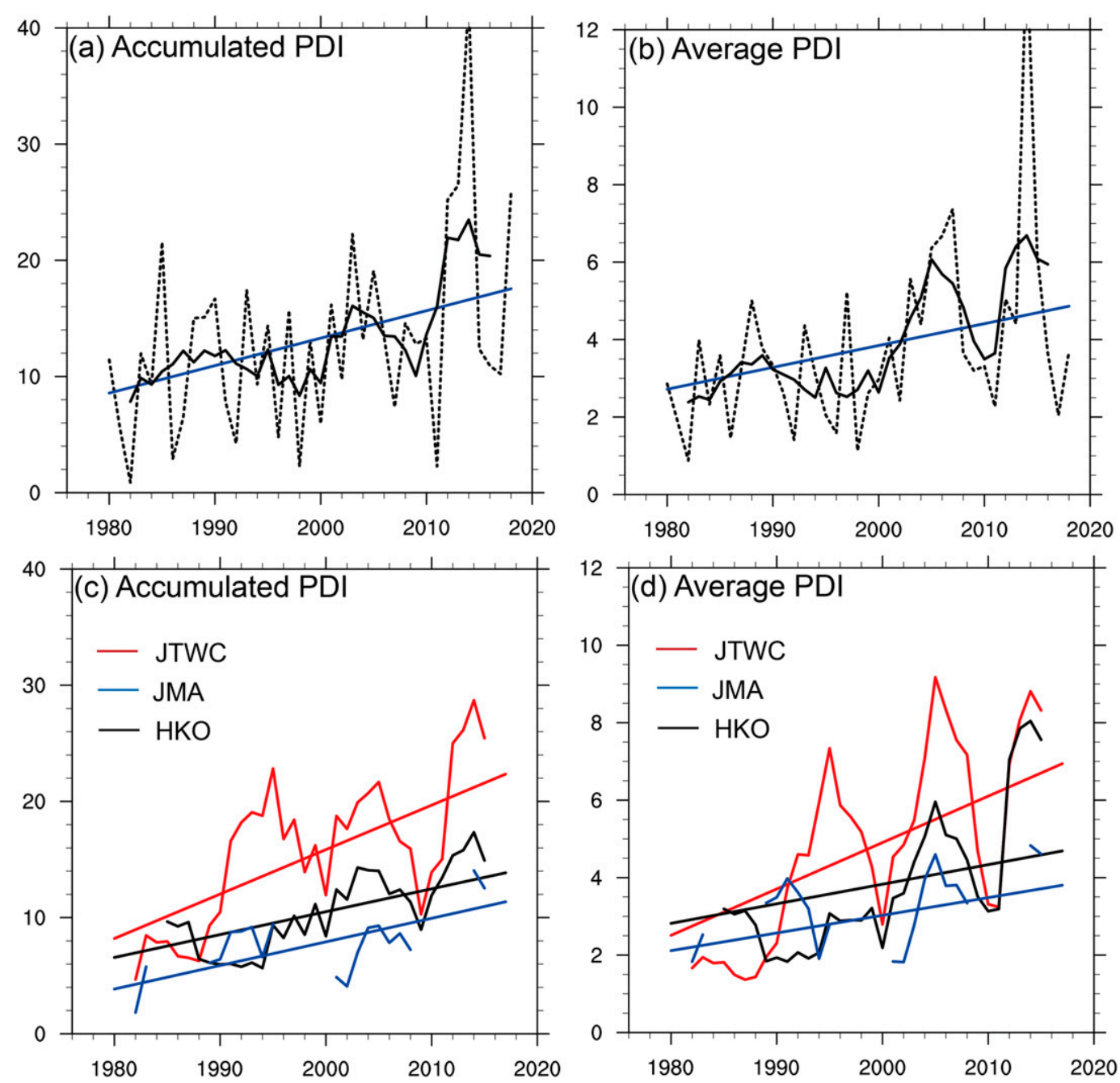

FIG. 1. Time series of (left) accumulated PDI $\left(10^{5} \mathrm{~m}^{3} \mathrm{~s}^{-3}\right)$ and (right) average PDI $\left(10^{5} \mathrm{~m}^{3} \mathrm{~s}^{-3}\right)$ from (a), (b) the CMA dataset and (c),(d) the JTWC, JMA, and HKO datasets for landfalling TCs in the peak typhoon season of June-October during 1980-2018. In (a) and (b), thick black lines are the 5-yr running average and blue lines indicate the corresponding linear trends. In (c) and (d), thick lines are the 5-yr running average and the corresponding linear trends.

decrease during 2011-17 (Fig. 2b). This could be related to the previously identified climate shift associated with the interdecadal Pacific oscillation (IPO; e.g., Henley et al. 2015; Meehl et al. 2016; Zhao et al. 2018a,b) and will be briefly discussed in the last section.

Figures $3 \mathrm{~b}$ and $3 \mathrm{c}$ show the time series of the annual mean TC intensity at landfall and the mean intensity weakening rate after landfall. The TC intensity at landfall is identified as one of the key factors that contribute to the increasing mean overland duration (Fig. 3b), which is statistically significant over the $95 \%$ confidence level. This is because stronger TCs may survive for longer time over land. On the other hand, mean TC intensity weakening rate shows a slightly decreasing trend over land in the past 39 years (Fig. 3c). Although this trend is not statistically significant, it also contributes partly to the sustaining of TCs after landfall and thus the increasing mean overland duration. Therefore, the enhanced landfall intensity combined with the reduced weakening rate over land resulted in the increase in overland duration of landfalling TCs over mainland China. Note that the mean intensity weakening rate decreases more markedly during the period of 1980-2011, which is statistically significant over the $90 \%$ confidence level. However, the mean overland intensity weakening rate changed to increase sharply after 2011 while to decrease after 2015 . The extremely low weakening rate in 2011 (Fig. 3c) corresponds to the extremely weak landfall intensity (Fig. 3b), while the second extremely high weakening rate in 2015 (Fig. 3c) corresponds to the extremely high landfall intensity 

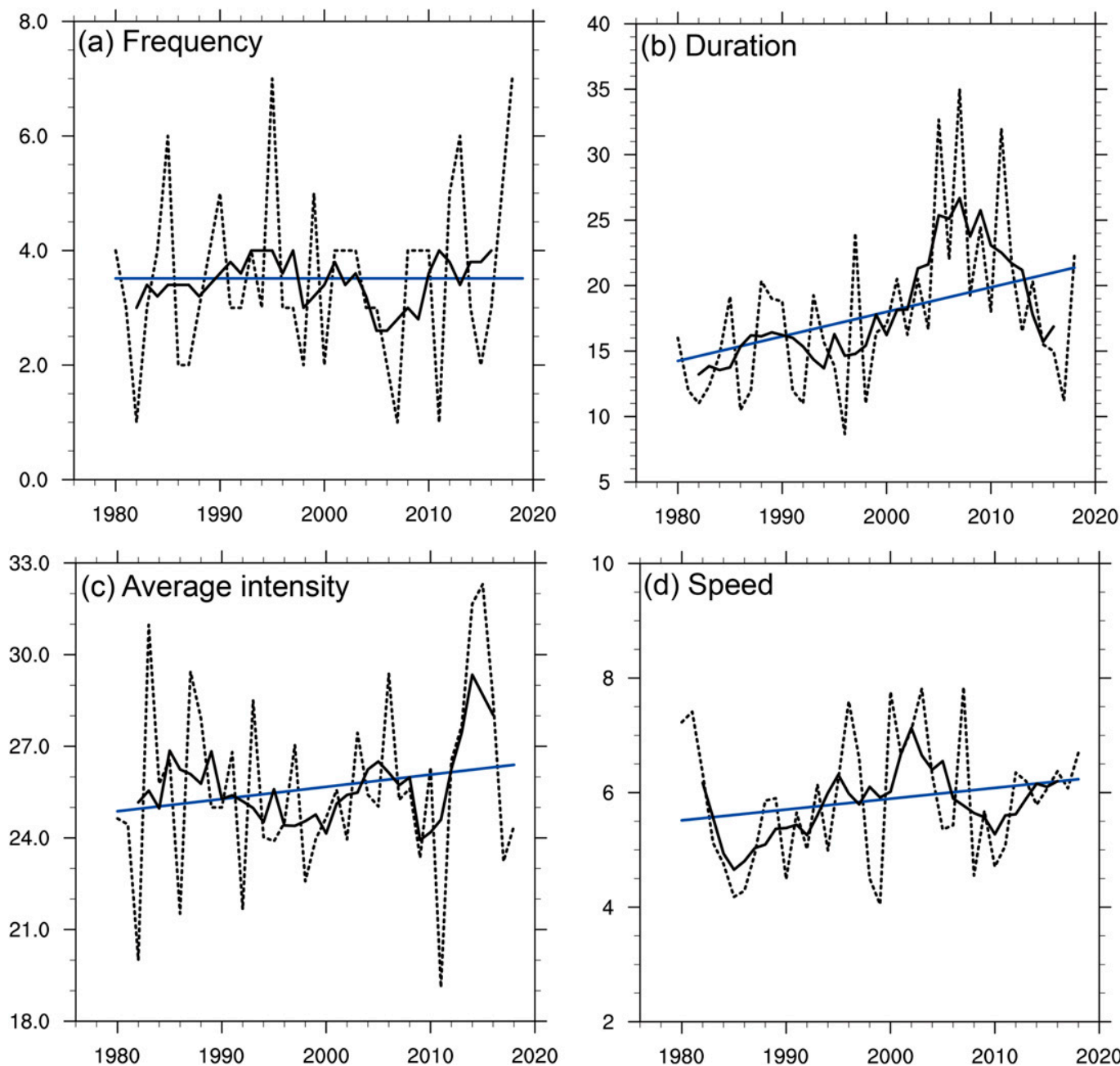

FIG. 2. Time series of the (a) number of landfalling TCs and the (b) average TC duration (h), (c) average intensity $\left(\mathrm{m} \mathrm{s}^{-1}\right)$, and (d) average translation speed $\left(\mathrm{m} \mathrm{s}^{-1}\right)$ after landfall in the peak typhoon season of June-October during 1980-2018. Thick black lines are the 5-yr running average, and the blue lines indicate the corresponding linear trends.

(Fig. 3b). This seems consistent with the empirical weakening rate model of TCs after landfall, which predicts an exponentially weakening rate of TC maximum sustained near-surface wind speed, developed in previous studies (e.g., Kaplan and DeMaria 1995, 2001; Wong et al. 2008). Namely, the weakening rate of TC intensity after landfall is roughly proportional to the TC intensity prior to and at landfall. In addition to the landfall intensity, some other factors may also affect the weakening rate, such as the landward translation speed, land surface conditions (soil moisture, land surface temperature, terrain, etc.), and environmental vertical wind shear (Kaplan and DeMaria 1995, 2001; Wong et al. 2008), as will be discussed in section 4 .

Figure $3 \mathrm{~d}$ shows the averaged track density (contours) of TCs making landfall over mainland China and its trend (shading) for the period 1980-2018. Here the track density is defined as the occurrence frequency of TCs that made landfall over mainland China and passed through a $5^{\circ} \times 5^{\circ}$ grid box. Note that when two time (6 hourly) points from one TC occurred in one grid box, we counted them twice in the track density. As we can see from Fig. 3d, a high mean track density centered over the northern South China Sea and southern coast of South China, indicating that climatologically landfalling TCs occurred frequently over these regions. During this period, there is a positive trend to the north-northeast of the center, implying that the track density of landfalling TCs shifted north-northeastward. This means that more TCs made landfall over the eastern and southeastern coasts of mainland China since 1980. This trend in TC landfall location over East Asia is consistent with that found by Wu et al. (2005), Tu et al. (2009), and Park et al. (2011). 

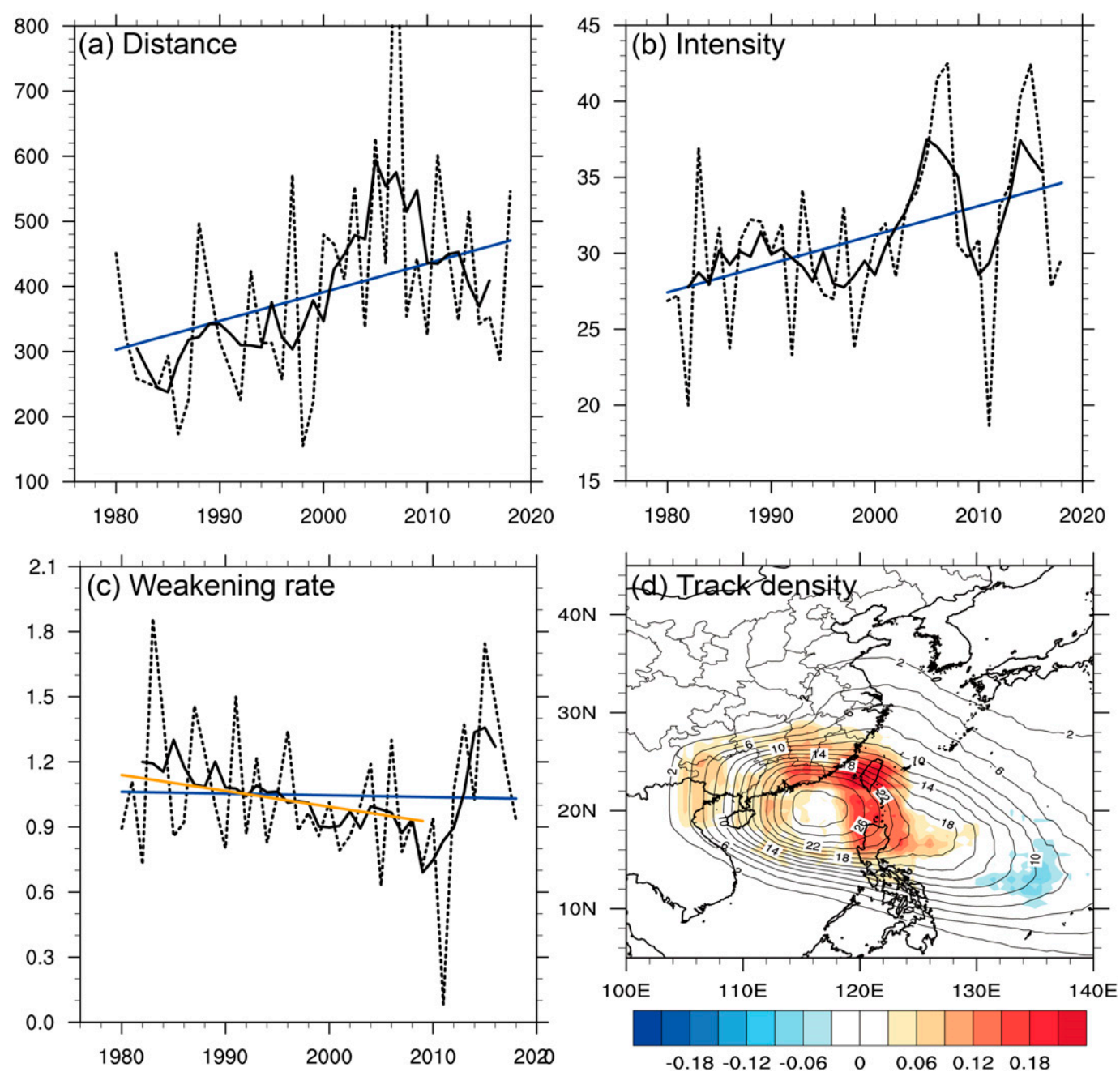

FIG. 3. Time series of (a) distance ( $\mathrm{km}$ ) after landfall, (b) TC intensity at landfall $\left(\mathrm{m} \mathrm{s}^{-1}\right)$, (c) intensity weakening rate $\left(\mathrm{m} \mathrm{s}^{-1} \mathrm{~h}^{-1}\right)$ over land, and (d) distribution of average TC track density (contours) and its linear trend (shaded; $\mathrm{yr}^{-1}$ ) in the peak typhoon season of June-October during 1980-2018. In (a)-(c), the thick black lines are the 5-yr running average and the blue lines indicate the corresponding linear trends during 1980-2018. The orange line in (c) indicates the linear trend during 1980-2009.

The northward shift of landfalling TC track density might have contributed to landfalling TC characteristics, such as the overland intensity weakening rate, because of different topography distributions between the northern and southern areas in the coastal region of mainland China. As hypothesized by Kaplan and DeMaria (2001), higher terrain near the coast may be more detrimental to TC structure and intensity and thus could lead to faster weakening rate of TCs after landfall. Therefore, we examined the topographic map of China (e.g., see Fig. 1 in Ying et al. 2011), which shows quite different land surface characteristics between the northern (north of $27^{\circ} \mathrm{N}$ ) and southern (south of $27^{\circ} \mathrm{N}$ ) areas in the coastal region of mainland China. The northern area is covered by wide plain with relatively less terrain, while the southern area is covered with complex hills and mountains and is subject to relatively larger surface roughness and higher surface frictional effect as well as more destructive to TC structure. It is thus expected that on average the overland weakening rate of TCs making landfall in the northern area would be slower than that in the southern area. To examine such possible topographic effect, we compared in Table 1 the climatological characteristics of landfalling TCs in the southern and northern areas during 1980-2018. We can see from Table 1 that the mean overland duration is longer, the mean traveling distance is farther, landfall intensity is higher, and the overland weakening rate is smaller in the northern area than in the southern area. As a result, the average PDI is much higher in the northern area than in the southern area. Therefore, in 
TABLE 1 . The climatologically averaged characteristics of landfall TCs in the southern (south of $27^{\circ} \mathrm{N}$ ) and northern (north of $27^{\circ} \mathrm{N}$ ) areas of mainland China during 1980-2018. Boldface and italic fonts indicate that the differences between northern TCs and southern TCs are statistically significant over the $90 \%$ and $95 \%$ confidence level, respectively, on the basis of Student's $t$ test.

\begin{tabular}{ccccccc}
\hline \hline Lat & $\begin{array}{c}\text { Avg PDI } \\
\left(\mathrm{m}^{3} \mathrm{~s}^{-3}\right)\end{array}$ & $\begin{array}{c}\text { Duration } \\
(\mathrm{h})\end{array}$ & $\begin{array}{c}\text { Distance } \\
(\mathrm{km})\end{array}$ & $\begin{array}{c}\text { Intensity } \\
\left(\mathrm{m} \mathrm{s}^{-1}\right)\end{array}$ & $\begin{array}{c}\text { Translation } \\
\left(\mathrm{m} \mathrm{s}^{-1}\right)\end{array}$ & $\begin{array}{c}\text { Weakening rate } \\
\left(\mathrm{m} \mathrm{s}^{-1} \mathrm{~h}^{-1}\right)\end{array}$ \\
\hline$\geq 27^{\circ} \mathrm{N}$ (north) & $4.6 \times 10^{5}$ & 23.35 & 493 & $\mathbf{3 3}$ & 21.63 & -0.834 \\
$<27^{\circ} \mathrm{N}$ (south) & $3.3 \times 10^{5}$ & 15.5 & 337 & $\mathbf{3 0}$ & 21.72 & -1.129 \\
\hline
\end{tabular}

addition to the increasingly conducive large-scale environmental conditions as will be discussed in the next section, the northward shift of landfall TC tracks together with the less pronounced orographic effect in the northern area contributed considerably to the increase in the mean overland duration, landfall intensity, and decrease in overland weakening rate, and thus the increase in destructive potential of landfall TCs in China in recent decades. We will show in the next section that the northward shift of TC track results mainly from changes in large-scale steering flow.

Note that Chen et al. (2011) showed that the mean landfall TC intensity changed little during the period 1975-2009, but we show a markedly increasing trend of the mean landfall TC intensity from 1980 to 2018 (Fig. 3b). Moreover, the trend of mean translation speed over land is also different (Fig. 2d). One reason for the difference is the different periods in the two studies. It can be seen from Fig. $3 b$ that there is a decadal fluctuation and no significant change during 1980-2003, which was similar to that in Chen et al. (2011). However, after 2005 there are two peaks in the annual mean landfall TC intensity and the trend changed upward sharply. Another reason is that we have focused on the peak typhoon season between June-October, while Chen et al. (2011) used July-October as the peak typhoon season. Therefore, there are some differences between our results and those in Chen et al. (2011). Nevertheless, our results are consistent with $\mathrm{Li}$ et al. (2017), who showed a significant increase in landfalling TC intensity over East China.

\section{Trend analysis for the related large-scale environmental conditions}

The trend in the characteristics of landfalling TCs over mainland China should be related to changes in the large-scale circulation and the underlying surface conditions. Figure 4 illustrates the linear trends in some key surface variables that may affect TC activities over the nearshore oceans and TC behaviors after landfall over mainland China. They are SST, soil temperature and moisture, and specific humidity averaged in the lower troposphere between the surface and $700 \mathrm{hPa}$. There is a significant warming trend in SST in the coastal oceans near East Asia, particularly offshore of mainland China (Fig. 4a). The warming SST conveyed an increasing energy supply to TCs before they made landfall (e.g., Emanuel 2005; Mei and Xie 2016; Li et al. 2017; Zhao et al. 2018a), favorable for stronger TCs at landfall. The linear correlation between mean landfalling intensity and nearshore SST is statistically significant over $95 \%$ confidence level. Similar to SST, both soil temperature and moisture (Figs. 4b,c), as well as the lowertropospheric specific humidity (Fig. 4d), all show increasing trends in the coastal region of mainland China. Similarly, the linear correlation between the mean duration after landfall and these underlying surface conditions are all statistically significant over the $90 \%$ confidence level. Previous studies have demonstrated that the surface evaporation and surface temperature are critical for TC maintenance over land (Tuleya and Kurihara 1978; Tuleya et al. 1984; Tuleya 1994). As shown in Tuleya (1994), warm land surface and high soil moisture are favorable for surface enthalpy flux and thus may slow down the weakening of a TC after landfall. Therefore, the increasing trends in land surface temperature and soil moisture provide more favorable surface thermodynamic conditions for TCs to survive longer after their landfall over mainland China (Li and Chen 2005; Park et al. 2011; Zhang et al. 2011; L. Liu et al. 2019).

Figure 5 shows the trends in some dynamical factors that are often considered important to TC intensity change, including the deep-layer vertical wind shear between 200 and $850 \mathrm{hPa}$ and low-level vertical wind shear between 700 and $1000 \mathrm{hPa}$ (e.g., Wang et al. 2015), upper-tropospheric divergence, and vertical $p$ velocity at $500 \mathrm{hPa}$. The deep-layer vertical wind shear shows a decreasing trend over mainland China, but the trends in the region affected by landfalling TCs are statistically significant only in a small area in the coastal region of South China (Fig. 5a). However, a significant decreasing trend in low-level vertical wind shear appears over Southeast China and neighboring offshore seas (Fig. 5b). Wang et al. (2015) found that the low-level vertical wind shear has a more pronounced detrimental effect on TC intensity over the WNP. Therefore, the weakening lowlevel vertical wind shear is favorable for intense TCs in 
(a) SST

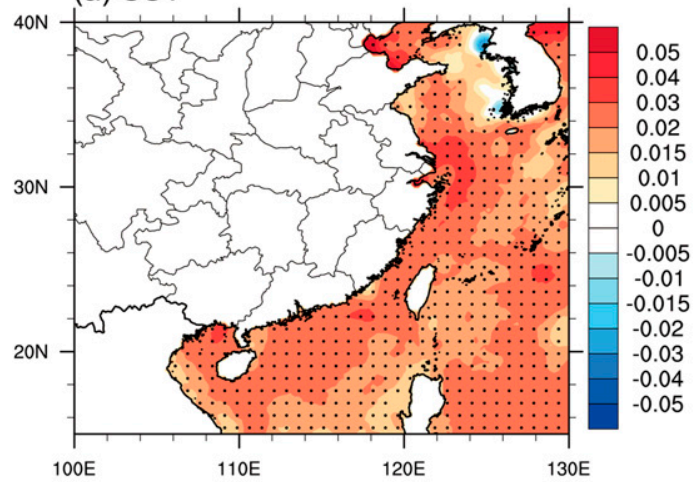

(c) Soil moisture

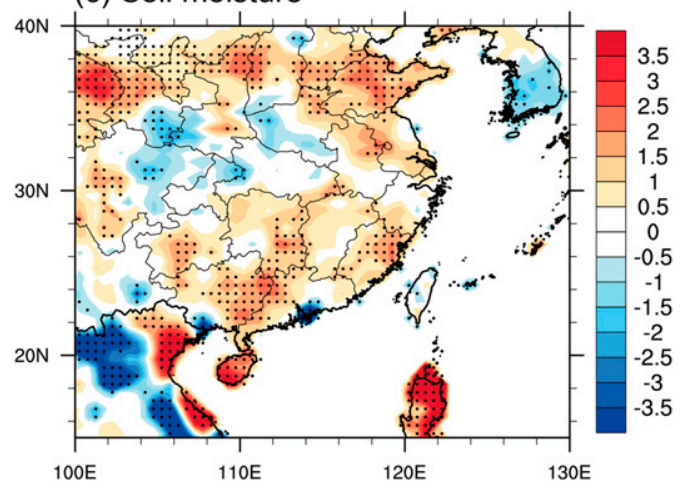

(b) Soil temperature

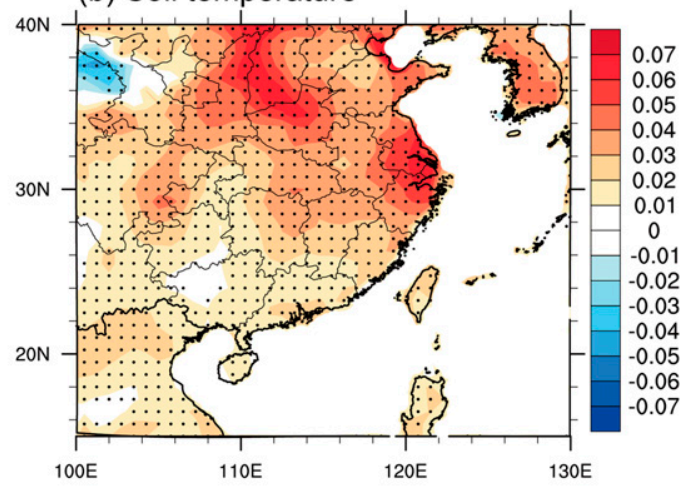

(d) Specific humidity

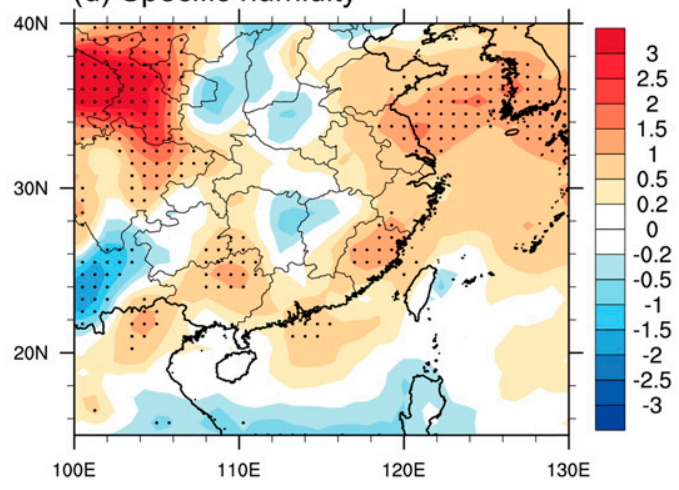

FIG. 4. Linear trends of (a) SST $\left(\mathrm{K} \mathrm{yr}^{-1}\right)$, (b) soil temperature $\left(\mathrm{K} \mathrm{yr}^{-1}\right)$, (c) soil moisture $\left(\mathrm{g} \mathrm{kg}^{-1} \mathrm{yr}^{-1}\right)$, and (d) specific humidity $\left(10^{-2} \mathrm{~g} \mathrm{~kg}^{-1} \mathrm{yr}^{-1}\right)$ averaged between the surface and $700 \mathrm{hPa}$ in the peak typhoon season of June-October during the period 1980-2018. Regions with trends that are significant over $90 \%$ confidence are shown with dots.

the coastal oceans and for TCs to sustain after landfall, thus contributing to the increasing mean duration over land and destructive potential of landfalling TCs over mainland China. The upper troposphere shows an increasing divergence over Southeast China and neighboring seas (Fig. 5c), which is also conducive to the maintenance of TC intensity, thus contributing to the decrease in overland intensity weakening rate and the increase in mean overland duration of landfalling TCs. In addition, there is a significant increasing trend in ascending motion at $500 \mathrm{hPa}$ over Southeast China and neighboring seas (Fig. 5d), which is dynamically consistent with the increasing trends in upper-level divergence and low-level convergence (not shown). These conditions are favorable for landfalling TCs to be stronger at landfall and survive longer over land after landfall (e.g., Park et al. 2011). Therefore, both thermodynamic conditions (including SST, land surface temperature and soil moisture, and low-level specific humidity) and dynamical conditions (such as low-level vertical wind shear) become more favorable for stronger landfalling TCs over the neighboring seas and for TCs survive longer after landfall over Southeast China.
Most previous studies related to changes in landfalling TCs have paid attentions to deep-layer vertical wind shear (Li et al. 2017; Chen et al. 2011; Park et al. 2011). However, we found the importance of low-level vertical wind shear to landfalling TCs over mainland China, which is consistent with the findings of Wang et al. (2015). They compared the correlation between vertical wind shear between different vertical layers and TC intensity change over the WNP. They found that the low-level shear between 700 and $1000 \mathrm{hPa}$ was more destructive to TCs than the commonly used deep-layer vertical wind shear between 200 and $850 \mathrm{hPa}$ in the active typhoon season over the WNP. To understand what caused the significant decrease in low-level vertical wind shear, we examined the long-term mean and the corresponding linear trend of horizontal winds at 700 and $1000 \mathrm{hPa}$ in the peak typhoon season during 1980-2018 (Fig. 6). It can be seen from Figs. 6a and 6c that the lowlevel shear is predominantly southwesterly and is dominated by southwesterly wind at $700 \mathrm{hPa}$ over Southeast China. The winds at $700 \mathrm{hPa}$ show a cyclonic trend centered between Taiwan and Luzon Islands over the WNP (Fig. 6b), while the winds at $1000 \mathrm{hPa}$ show little 
(a) VWS $850 \mathrm{hPa}-200 \mathrm{hPa}$

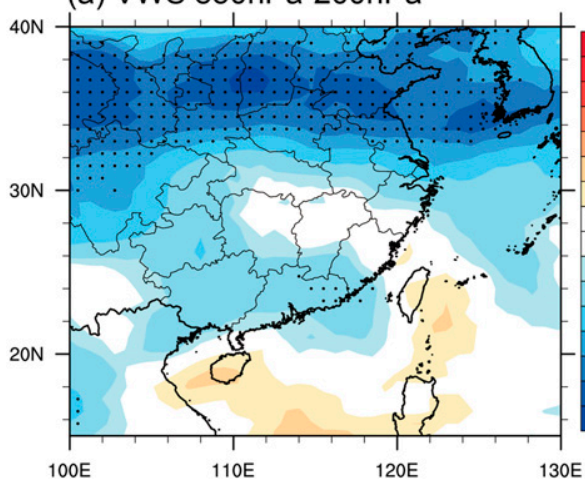

(c) DIV 200hPa

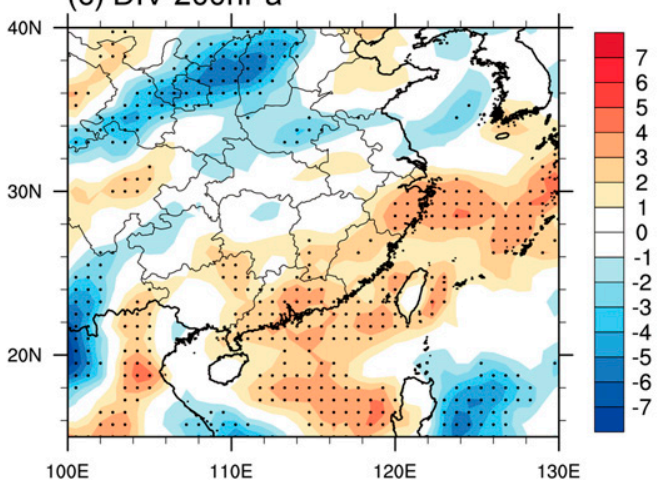

(b) VWS $1000 \mathrm{hPa}-700 \mathrm{hPa}$

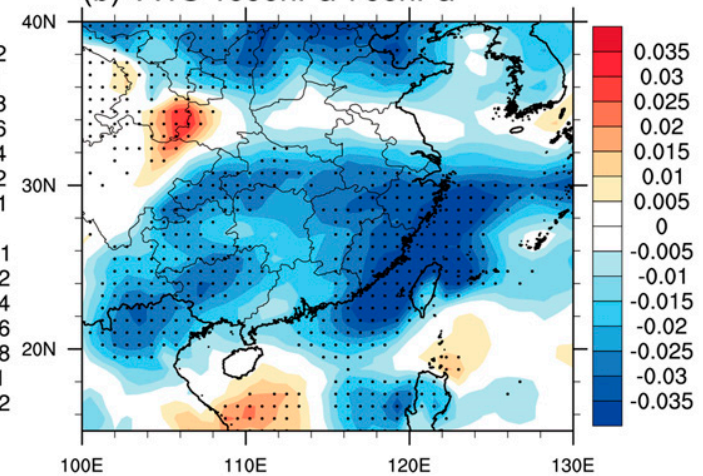

(d) Vertical wind $500 \mathrm{hPa}$

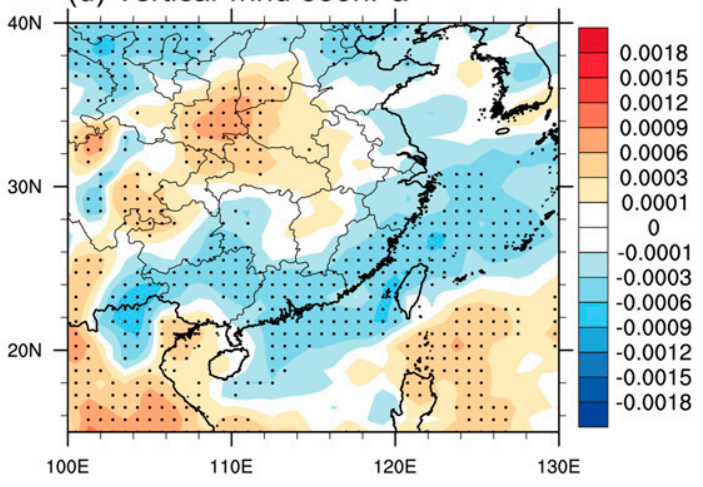

FIG. 5. Linear trends of (a) deep-layer vertical wind shear $\left(\mathrm{m} \mathrm{s}^{-1} \mathrm{yr}^{-1}\right)$ between 850 and $200 \mathrm{hPa}$, (b) low-level vertical wind shear $\left(\mathrm{m} \mathrm{s}^{-1} \mathrm{yr}^{-1}\right)$ between 1000 and $700 \mathrm{hPa}$, (c) upper-tropospheric divergence $\left(10^{-6} \mathrm{~s}^{-1} \mathrm{yr}^{-1}\right)$ at $200 \mathrm{hPa}$, and (d) vertical motion at $500 \mathrm{hPa}\left(\mathrm{Pa} \mathrm{s}^{-1} \mathrm{yr}^{-1}\right)$ in the peak typhoon season of June-October during 19802018. Regions with trends that are significant over the $90 \%$ confidence level are shown with dots.

trend over Southeast China but a southwesterly trend in the nearshore seas of mainland China (Fig. 6d). Although trends that are statistically significant appear in relatively small area at both levels, the decreasing trends in vertical shear between the two levels are statistically significant over Southeast China and neighboring seas (Fig. 5b). Note that the northeasterly trends at $700 \mathrm{hPa}$ over mainland China implies the weakening of the southwesterly summer monsoon over East Asian. This seems to suggest that the decrease in low-level vertical wind shear is mainly due to the weakening of the East Asian summer monsoon, which in turn is a response to global climate change (e.g., Wang 2001; Zhu et al. 2012; Y. Liu et al. 2019).

To understand what caused the northward shift of landfalling TC tracks over mainland China, we analyzed changes in the steering flow, which is defined as the deep-layer mean winds between 300 and $850 \mathrm{hPa}$ (e.g., Holland 1984). Figure 7 shows the linear trend of the steering flow during 1980-2018, which is characterized by a prominent cyclonic circulation trend centered over Southeast China. The southeasterly steering flow trend to the east of Taiwan Island over the WNP is conducive to the northward shift of TC tracks. This feature was also found by Park et al. (2011) and Li et al. (2017). Therefore, the southeasterly flow was enhanced and steered more TCs toward the East China coast, and thus leading to the northward shift of landfalling TC tracks over mainland China. Such a northward shift of landfalling TC tracks might contribute to the decreasing trend in overland weakening rate of TCs after landfall because the lower topography in East China coast could insert less dissipation effect on landfalling TCs than the higher topography in the southern area of Southeast China.

\section{Conclusions and discussion}

In this study, the long-term changes in destructive potential of landfalling TCs over mainland China during the period of 1980-2018 are investigated. It is found that both the accumulated PDI and average PDI increased with statistical significance over $90 \%$ confidence level, implying that the destructive potential of individual landfalling TCs has been increasing over the past 39 years. No apparent trend in the landfalling TC frequency 
(a) $700 \mathrm{hPa}$ average

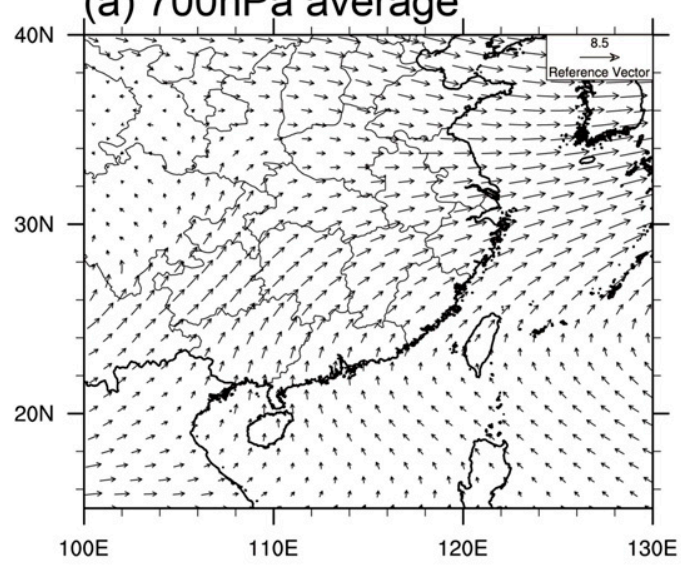

(c) $1000 \mathrm{hPa}$ average

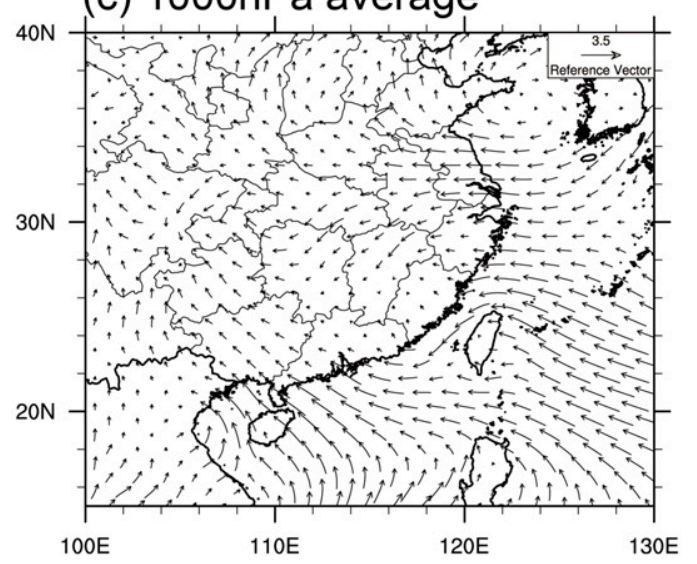

(b) $700 \mathrm{hPa}$ trend

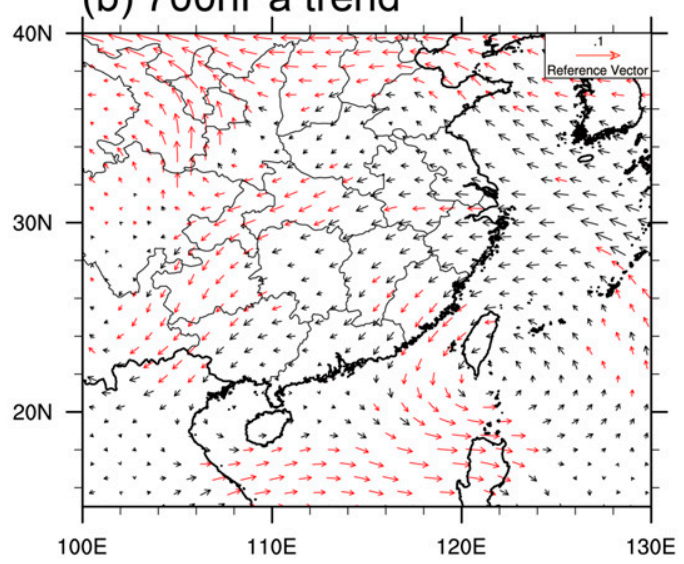

(d) $1000 \mathrm{hPa}$ trend

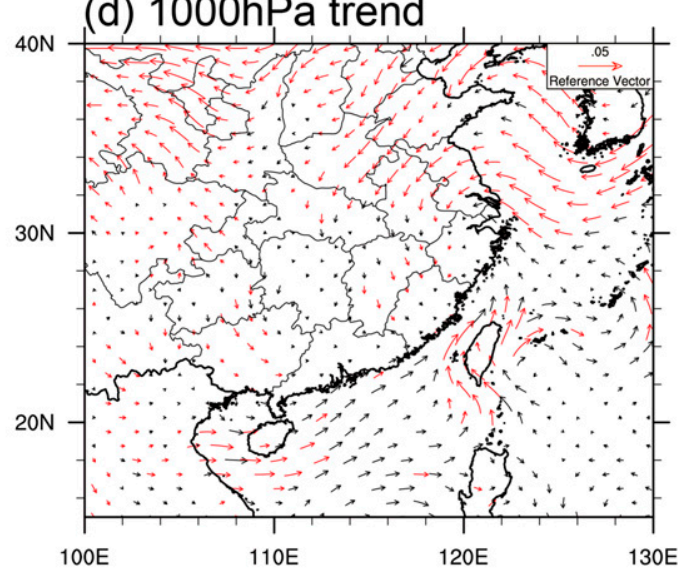

FIG. 6. The climatological mean winds $\left(\mathrm{m} \mathrm{s}^{-1}\right.$ ) at (a) 700 and (c) $1000 \mathrm{hPa}$, and (b),(d) their respective trends $\left(\mathrm{m} \mathrm{s}^{-1} \mathrm{yr}^{-1}\right)$ in the peak typhoon season of June-October during 1980-2018. The trend vectors in red indicate the trends that are statistically significant over the $90 \%$ confidence level.

over mainland China occurred over the past 39 years. Different from the results of Li et al. (2017), who found that the increasing PDI over East China was mainly due to the increases in both landfall frequency and landfall intensity, our results show that the increasing trends in both the accumulated and average PDI are largely contributed by the significant increasing trends in the mean overland duration as well as the weak increasing trend of mean intensity of TCs at landfall. We show that, in addition to the increase in traveling distance, the increase in landfall intensity, the decrease in intensity weakening rate after landfall, and the northward shift of track density over mainland China all contributed to the increasing mean overland duration of TCs after landfall, and thus the increase in accumulated and average PDI. This is also different from the results of Chen et al. (2011), who found that the slowing translation speed and longer distance over land were the primary reasons for the longer duration after landfall.

Both dynamic and thermodynamic conditions are examined to explore factors that contributed to the observed increasing destructive potential of landfalling TCs over mainland China. Results show that the warming SST in the coastal region of mainland China provided favorable conditions for increasing TC intensity prior to and at landfall, where the linear correlation between landfalling intensity and nearshore SST is statistically significant over $95 \%$ confidence level. The increases in land surface temperature and soil moisture and the lower tropospheric humidity are thermodynamic conditions favorable for increasing mean overland duration of TCs after landfall. The decreasing vertical wind shear (in particular, the decreasing low-level vertical wind shear), the increasing upper-tropospheric divergence, and midlevel upward motion are dynamical conditions favorable for increasing TC intensity at landfall and also for decreasing the overland weakening rate after landfall, contributing to the increasing mean overland duration after landfall and thus the increasing PDI of landfalling TCs over mainland China. It is worth noting that the decrease in low-level vertical wind shear, 


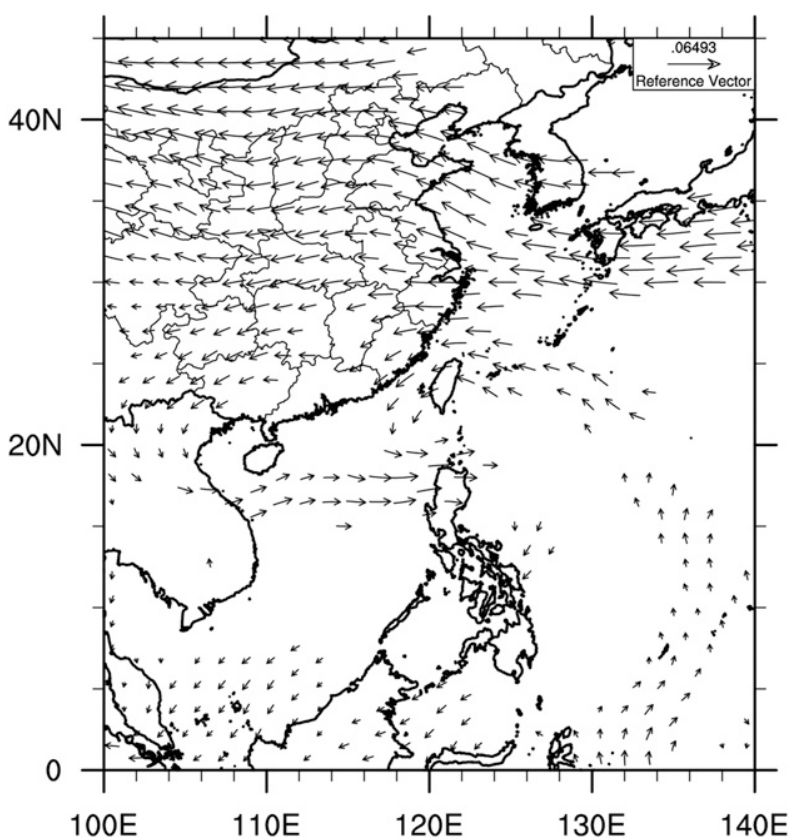

FIG. 7. Linear trends of steering flow $\left(\mathrm{m} \mathrm{s}^{-1} \mathrm{yr}^{-1}\right)$ averaged between 850 and $300 \mathrm{hPa}$ during 1980-2018. Only vectors that are statistically significant at the $90 \%$ confidence level are plotted.

which was mainly associated with the weakening of the East Asian summer monsoon, was more important than deep-layer vertical wind shear to the trends in landfalling TC characteristics over mainland China. Moreover, the northward shift of TC tracks was primarily contributed by the increasing southeasterly flow over the WNP.

Note that this study has focused on the analysis of long-term trends in the observed destructive potential of landfalling TCs over mainland China based on data between 1980 and 2018. Since the limited period was analyzed due to TC intensity quality, we could not exclude the possible contamination of the trends obtained in this study by the overlaid decadal/interdecadal Pacific oscillations (PDO/IPO). Many previous studies have shown that the IPO changed its positive phase to negative phase around 1998 (e.g., Henley et al. 2015; Meehl et al. 2016) and from the recent negative phase to a new positive phase around 2013 (see Fig. 6 in Zhao et al. 2018b). The recent negative phase of the IPO (19982013) is characterized by a La Niña-like SST anomaly pattern in the tropical Pacific with more significant warming in the northwest and southwest Pacific (e.g., Zhao et al. 2018a,b). This SST anomaly pattern strengthened the Walker circulation and cyclonic circulation over the western WNP and has been shown to have contributed significantly to the increased occurrence of intense TCs in the coastal regions along East Asia since 1998 (Mei and Xie 2016; Zhao et al. 2018a). Note that in addition to the long-term trends in the landfalling TC characteristics discussed in this study, the landfalling TC characteristics might also have been affected by interdecadal climate variability, such as the IPO. However, no changes were consistent with the IPO phase changes mentioned above. This may indicate that the trend analysis of landfalling TC characteristics over mainland China has not been strongly affected by IPO. Nevertheless, whether the IPO has any significant effect on the landfalling TC characteristics over mainland China is a topic reserved for a future study with longer data and suitable analysis method.

Note that this study has only considered TCs with maximum sustained wind speed exceeding $17.2 \mathrm{~m} \mathrm{~s}^{-1}$. Tropical depressions could also be destructive by causing torrential rainfall inland, but they have not been included in this study. In those situations, scale interactions between TC vortex and other large-scale and synoptic weather systems are often very important. In addition, whether and to what degree the landfalling TC characteristics may affect the TC-induced precipitation changes are also topics that can be investigated in the future.

Acknowledgments. Thanks are given to Dr. Hu Hao for providing the landfalling information of TCs. This study has been supported in part by the National Key R\&D Program of China under Grants 2017YFC1501602 and in part by the National Natural Science Foundation of China under Grants 41675044, 41705027, 41730960, and 41875114. The TC best-track data were obtained from STI/CMA (http://tcdata.typhoon.org.cn). The ECMWF data used in this study were obtained online (http:// apps.ecmwf.int/datasets/). The soil moisture dataset used in this study was also obtained online (https:// www.esrl.noaa.gov/psd/data/gridded/data.cpcsoil.html). All figures were produced using the NCAR Command Language (NCL).

\section{REFERENCES}

Camargo, S. J., and A. H. Sobel, 2005: Western North Pacific tropical cyclone intensity and ENSO. J. Climate, 18, 29963006, https://doi.org/10.1175/JCLI3457.1.

Chen, X., L. Wu, and J. Zhang, 2011: Increasing duration of tropical cyclones over China. Geophys. Res. Lett., 38, L02708, https://doi.org/10.1029/2010GL046137.

Dee, D. P., and Coauthors, 2011: The ERA-Interim reanalysis: Configuration and performance of the data assimilation system. Quart. J. Roy. Meteor. Soc., 137, 553-597, https://doi.org/ 10.1002/qj.828.

Elsner, J. B., J. P. Kossin, and T. H. Jagger, 2008: The increasing intensity of the strongest tropical cyclones. Nature, 455, 92-95, https://doi.org/10.1038/nature07234.

Emanuel, K. A., 2005: Increasing destructiveness of tropical cyclones over the past 30 years. Nature, 436, 686-688, https:// doi.org/10.1038/nature03906. 
_ 2007: Environmental factors affecting tropical cyclone power dissipation. J. Climate, 20, 5497-5509, https://doi.org/10.1175/ 2007JCLI1571.1.

Henley, B. J., J. Gergis, D. J. Karoly, S. Power, J. Kennedy, and C. K. Folland, 2015: A tripole index for the interdecadal Pacific oscillation. Climate Dyn., 45, 3077-3090, https:// doi.org/10.1007/s00382-015-2525-1.

Holland, G. J., 1984: Tropical cyclone motion. A comparison of theory and observation. J. Atmos. Sci., 41, 68-75, https:// doi.org/10.1175/1520-0469(1984)041<0068:TCMACO >2.0. $\mathrm{CO} ; 2$.

Hu, H., Y.-H. Duan, Y. Wang, and X. Zhang, 2017: Diurnal cycle of rainfall associated with landfalling tropical cyclones in China from rain gauge observations. J. Appl. Meteor. Climatol., 56, 2595-2605, https://doi.org/10.1175/JAMC-D-16-0335.1.

Kaplan, J., and M. DeMaria, 1995: A simple empirical model for predicting the decay of tropical cyclone winds after landfall. J. Appl. Meteor., 34, 2499-2512, https://doi.org/10.1175/15200450(1995)034<2499:ASEMFP>2.0.CO;2.

— landfall in the New England area. J. Appl. Meteor., 40, 280-286, https://doi.org/10.1175/1520-0450(2001)040<0280:OTDOTC $>$ 2.0.CO;2.

Klotzbach, P. J., 2006: Trends in global tropical cyclone activity over the past twenty years (1986-2005). Geophys. Res. Lett., 33, L10805, https://doi.org/10.1029/2006GL025881.

Knutson, T. R., and R. E. Tuleya, 2004: Impact of $\mathrm{CO}_{2}$-induced warming on simulated hurricane intensity and precipitation: Sensitivity to the choice of climate model and convective parameterization. J. Climate, 17, 3477-3495, https://doi.org/ 10.1175/1520-0442(2004)017<3477:IOCWOS > 2.0.CO;2.

— J. J. Sirutis, S. T. Garner, I. M. Held, and R. E. Tuleya, 2007: Simulation of the recent multidecadal increase of Atlantic hurricane activity using an 18-km-grid regional model. Bull. Amer. Meteor. Soc., 88, 1549-1565, https://doi.org/10.1175/ BAMS-88-10-1549.

- and Coauthors, 2010: Tropical cyclones and climate change. Nat. Geosci., 3, 157-163, https://doi.org/10.1038/ngeo779.

Kossin, J. P., K. R. Knapp, D. J. Vimont, R. J. Murnane, and B. A. Harper, 2007: A globally consistent reanalysis of hurricane variability and trends. Geophys. Res. Lett., 34, L04815, https:// doi.org/10.1029/2006GL028836.

Li, R. C., W. Zhou, C. M. Shun, and T. C. Lee, 2017: Change in destructiveness of landfalling tropical cyclones over China in recent decades. J. Climate, 30, 3367-3379, https://doi.org/ 10.1175/JCLI-D-16-0258.1.

Li, Y., and L.-S. Chen, 2005: Numerical study on impacts of boundary layer fluxes over wetland on sustention and rainfall of landfalling tropical cyclone (in Chinese). Acta Meteor. Sin., 63, 683-693.

Liu, L., J. Xu, Y. Wang, and Y.-H. Duan, 2019: Contribution of recycling of surface precipitation to landfalling tropical cyclone rainfall: A modeling study for Typhoon Utor (2013). J. Geophys. Res. Atmos., 124, 870-885, https://doi.org/10.1029/ 2018JD029380.

Liu, Y., and Coauthors, 2019: Anthropogenic aerosols cause recent pronounced weakening of Asian Summer Monsoon relative to last four centuries. Geophys. Res. Lett., 46, 5469-5479, https:// doi.org/10.1029/2019GL082497.

Meehl, G. A., A. Hu, B. D. Santer, and S.-P. Xie, 2016: Contribution of the Interdecadal Pacific Oscillation to twentieth-century global surface temperature trends. Nat. Climate Change, $\mathbf{6}$, 1005-1008, https://doi.org/10.1038/nclimate3107.
Mei, W., and S.-P. Xie, 2016: Intensification of landfalling typhoons over the northwest Pacific since the late 1970s. Nat. Geosci., 9, 753-757, https://doi.org/10.1038/ngeo2792.

Park, D.-S. R., C.-H. Ho, J.-H. Kim, and H.-S. Kim, 2011: Strong landfall typhoons in Korea and Japan in a recent decade. J. Geophys. Res., 116, D07105, https://doi.org/10.1029/ 2010JD014801.

,,--- , and 2013: Spatially inhomogeneous trends of tropical cyclone intensity over the western North Pacific for 1977-2010. J. Climate, 26, 5088-5101, https://doi.org/10.1175/ JCLI-D-12-00386.1.

,-- , and — 2014: Growing threat of intense tropical cyclones to East Asia over the period 1977-2010. Environ. Res Lett., 9, 014008, https://doi.org/10.1088/1748-9326/9/1/014008.

Pielke, R. A., Jr., J. Gratz, C. W. Landsea, D. Collins, M. A. Saunders, and R. Musulin, 2008: Normalized hurricane damage in the United States: 1900-2005. Nat. Hazards Rev., 9, 29 42, https://doi.org/10.1061/(ASCE)1527-6988(2008)9:1(29).

Powell, M. D., and T. A. Reinhold, 2007: Tropical cyclone destructive potential by integrated kinetic energy. Bull. Amer. Meteor. Soc., 88, 513-526, https://doi.org/10.1175/BAMS-88-4513.

Trenberth, K., 2005: Uncertainty in hurricanes and global warming Science, 308, 1753-1754, https://doi.org/10.1126/science.1112551.

Tu, J. Y., C. Chou, and P.-S. Chu, 2009: The abrupt shift of typhoon activity in the vicinity of Taiwan and its association with western North Pacific-East Asian climate change. J. Climate, 22, 3617-3628, https://doi.org/10.1175/2009JCLI2411.1.

Tuleya, R. E., 1994: Tropical storm development and decay: Sensitivity to surface boundary conditions. Mon. Wea. Rev., 122, 291-304, https://doi.org/10.1175/1520-0493(1994)122<0291: TSDADS $>2.0 . \mathrm{CO} ; 2$.

— , and Y. Kurihara, 1978: A numerical simulation of the landfall of tropical cyclones. J. Atmos. Sci., 35, 242-257, https://doi.org/ 10.1175/1520-0469(1978)035<0242:ANSOTL $>2.0$.CO;2.

— M. A. Bender, and Y. Kurihara, 1984: A simulation study of the landfall of tropical cyclones. Mon. Wea. Rev., 112, 124-136, https://doi.org/10.1175/1520-0493(1984)112<0124:ASSOTL > 2.0.CO;2.

Wang, H.-J., 2001: The weakening of the Asian monsoon circulation after the end of 1970's. Adv. Atmos. Sci., 18, 376-386, https://doi.org/10.1007/BF02919316.

Wang, Y., Y.-J. Rao, Z.-M. Tan, and D. Schönemann, 2015: A statistical analysis of the effects of vertical wind shear on tropical cyclone intensity change over the western North Pacific. Mon. Wea. Rev., 143, 3434-3453, https://doi.org/ 10.1175/MWR-D-15-0049.1.

Webster, P. J., G. J. Holland, J. A. Curry, and H. R. Chang, 2005: Changes in tropical cyclone number, duration, and intensity in a warming environment. Science, 309, 1844-1846, https:// doi.org/10.1126/science.1116448.

Wong, M. L., J. C.-L. Chan, and W. Zhou, 2008: A simple empirical model for estimating the intensity change of tropical cyclones after landfall along the South China coast. J. Appl. Meteor. Climatol., 47, 326-338, https://doi.org/10.1175/2007JAMC1633.1.

Wu, L., B. Wang, and S. Geng, 2005: Growing typhoon influence on East Asia. Geophys. Res. Lett., 32, L18703, https://doi.org/ 10.1029/2005GL022937.

$\longrightarrow, \ldots$, and S. A. Braun, 2008: Implications of tropical cyclone power dissipation index. Int. J. Climatol., 28, 727-731, https:// doi.org/10.1002/joc.1573.

Ying, M., B. Chen, and G. Wu, 2011: Climate trends in tropical cyclone-induced wind and precipitation over mainland China. 
Geophys. Res. Lett., 38, L01702, https://doi.org/10.1029/ 2010 GL045729.

- W. Zhang, H. Yu, X. Lu, J. Feng, Y. Fan, Y. Zhu, and D. Chen, 2014: An overview of the China Meteorological Administration tropical cyclone database. J. Atmos. Oceanic Technol., 31, 287301, https://doi.org/10.1175/JTECH-D-12-00119.1.

Zhang, Q., L. Wu, and Q. Liu, 2009: Tropical cyclone damages in China 1983-2006. Bull. Amer. Meteor. Soc., 90, 489-496, https://doi.org/10.1175/2008BAMS2631.1.

Zhang, Y., C. Cassardo, C. Ye, M. Galli, and N. Vela, 2011: The role of the land surface processes in the rainfall generated by a landfall typhoon: A simulation of the Typhoon Sepat (2007). Asia-Pac. J. Atmos. Sci., 47, 63-77, https://doi.org/10.1007/ s13143-011-1006-7.
Zhao, J.-W., R.-F. Zhan, and Y. Wang, 2018a: Global warming hiatus contributed to the increased occurrence of intense tropical cyclones in the coastal regions along East Asia. Sci. Rep., 8, 6023, https://doi.org/10.1038/s41598-01824402-2.

,,--- , and H.-M. Xu, 2018b: Contribution of interdecadal Pacific oscillation to the recent abrupt decrease in tropical cyclone genesis frequency over the western North Pacific since 1998. J. Climate, 31, 8211-8224, https://doi.org/ 10.1175/JCLI-D-18-0202.1.

Zhu, C.-W., B. Wang, W.-H. Qian, and B. Zhang, 2012: Recent weakening of northern East Asian summer monsoon: A possible response to global warming. Geophys. Res. Lett., 39, L09701, https://doi.org/10.1029/2012GL051155. 